\title{
Peripatric speciation
}

Andrew Z. Colvin* et al.

\begin{abstract}
Peripatric speciation is a mode of speciation in which a new species is formed from an isolated peripheral population. ${ }^{[1]: 105}$ Since peripatric speciation resembles allopatric speciation, in that populations are isolated and prevented from exchanging genes, it can often be difficult to distinguish between them. ${ }^{[2]}$ Nevertheless, the primary characteristic of peripatric speciation proposes that one of the populations is much smaller than the other. The terms peripatric and peripatry are often used in biogeography, referring to organisms whose ranges are closely adjacent but do not overlap, being separated where these organisms do not occur-for example on an oceanic island compared to the mainland. Such organisms are usually closely related (e.g. sister species); their distribution being the result of peripatric speciation.

The concept of peripatric speciation was first outlined by the evolutionary biologist Ernst Mayr in $1954 \cdot{ }^{[3]}$ Since then, other alternative models have been developed such as centrifugal speciation, that posits that a species' population experiences periods of geographic range expansion followed by shrinking periods, leaving behind small isolated populations on the periphery of the main population. Other models have involved the effects of sexual selection on limited population sizes. Other related models of peripherally isolated populations based on chromosomal rearrangements have been developed such as budding speciation and quantum speciation.
\end{abstract}

The existence of peripatric speciation is supported by observational evidence and laboratory experiments. ${ }^{[1]: 106}$ Scientists observing the patterns of a species biogeographic distribution and its phylogenetic relationships are able to reconstruct the historical process by which they diverged. Further, oceanic islands are often the subject of peripatric speciation research due to their isolated habitats-with the Hawaiian Islands widely represented in much of the scientific literature.

\section{History}

Main article: History of speciation

Peripatric speciation was originally proposed by Ernst Mayr in 1954, ${ }^{[3]}$ and fully theoretically modeled in $1982 .{ }^{[4]}$ It is related to the founder effect, where small living populations may undergo selection bottlenecks. ${ }^{[5]}$ The founder effect is based on models that suggest peripatric speciation can occur by the interaction of selection and genetic drift, ${ }^{[1]: 106}$ which may play a significant role. ${ }^{[6]}$ Mayr first conceived of the idea by his observations of kingfisher populations in New Guinea and its surrounding islands. ${ }^{[1]: 389}$ Tanysiptera galatea was largely uniform in morphology on the mainland, but the populations on the surrounding islands differed significantly-referring to this pattern as "peripatric".[1]:389 This same pattern was observed by many of Mayr's contemporaries at the time such as by E. B. Ford's studies of Maniola jurtina. ${ }^{[7]: 522}$ Around the same time, the botanist Verne Grant developed a

*Author correspondence: azcolvin429@gmail.com Licensed under: CC-BY-SA

Received 15-04-2018; accepted 14-08-2018 model of quantum speciation very similar to Mayr's model in the context of plants. ${ }^{[8]}$

In what has been called Mayr's genetic revolutions, he postulated that genetic drift played the primary role that resulted in this pattern. ${ }^{[1]: 389}$ Seeing that a species cohesion is maintained by conservative forces such as epistasis and the slow pace of the spread of favorable alleles in a large population (based heavily on J. B. S. Haldane's calculations), he reasoned that speciation could only take place in which a population bottleneck occurred. [1]:389 A small, isolated, founder population could be established on an island for example. Containing less genetic variation from the main population, shifts in allele frequencies may occur from different selection pressures. ${ }^{[1]: 390}$ This leads to further changes in the network of linked loci, driving a cascade of genetic change, or a "genetic revolution"-a large-scale reorganization of the entire genome of the peripheral population. ${ }^{[1]: 391}$ Mayr did recognize that the chances of success were incredibly low and that extinction was likely; though noting that some examples of successful founder populations existed at the time. ${ }^{[7]: 522}$ 
Shortly after Mayr, William Louis Brown, Jr. proposed an alternative model of peripatric speciation in 1957 called centrifugal speciation. In 1976 and 1980, the Kaneshiro model of peripatric speciation was developed by Kenneth Y. Kaneshiro which focused on sexual selection as a driver for speciation during population bottlenecks. ${ }^{[9][10][11]}$

\section{Models}

\section{Peripatric}

Peripatric speciation models are identical to models of vicariance (allopatric speciation). ${ }^{[1]: 105}$ Requiring both geographic separation and time, speciation can result as a predictable byproduct. ${ }^{[12]}$ Peripatry can be distinguished from allopatric speciation by three key features: ${ }^{[1]: 105}$

- The size of the isolated population

- Strong selection caused by the dispersal and colonization of novel environments

- The effects of genetic drift on small populations.

The size of a population is important because individuals colonizing a new habitat likely contain only a small sample of the genetic variation of the original population. This promotes divergence due to strong selective pressures, leading to the rapid fixation of an allele within the descendant population. This gives rise to the potential for genetic incompatibilities to evolve. These incompatibilities cause reproductive isolation, giving rise to-sometimes rapid-speciation events. ${ }^{[1]: 105}$ Furthermore, two important predictions are invoked, namely that geological or climactic changes cause populations to become locally fragmented (or regionally when considering allopatric speciation), and that an isolated population's reproductive traits evolve enough as to prevent interbreeding upon potential secondary contact. ${ }^{[13]}$ The role of genetic drift and founder effects in speciation remains controversial and unresolved. ${ }^{[1]: 394-}$ 396

The peripatric model results in, what have been called, progenitor-derivative species pairs, whereby the derivative species (the peripherally isolated population)geographically and genetically isolated from the progenitor species-diverges. ${ }^{[14]}$ A specific phylogenetic signature results from this mode of speciation: the geographically widespread progenitor species becomes paraphyletic (thereby becoming a paraspecies), with re spect to the derivative species (the peripheral isolate). ${ }^{[1]: 470}$ The concept of a paraspecies is therefore a logical consequence of the evolutionary species con-
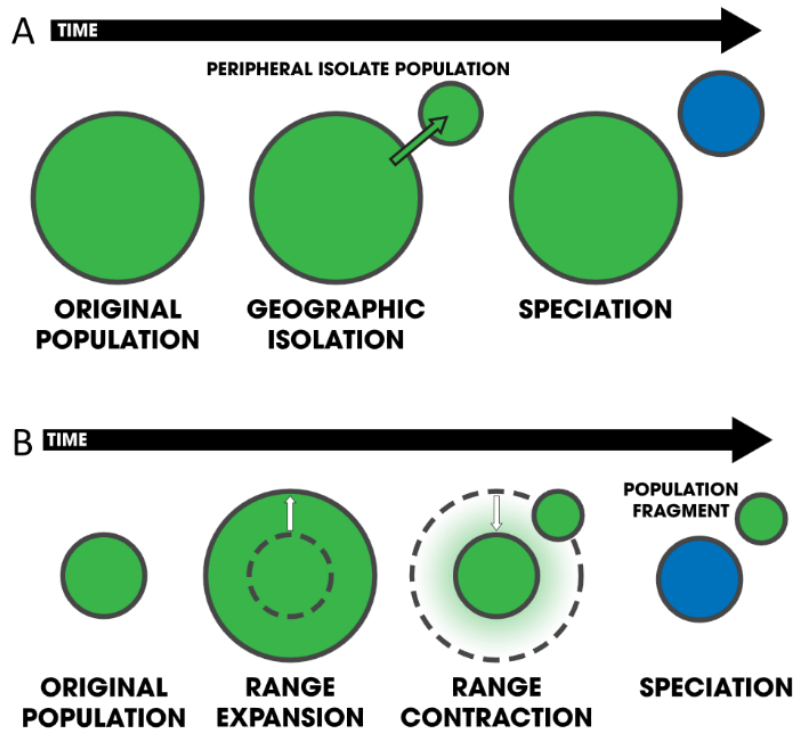

Figure 1 | Diagrams representing the process of peripatric and centrifugal speciation. A) In peripatry, a small population becomes isolated on the periphery of the central population evolving reproductive isolation (blue) due to reduced gene flow. B) In centrifugal speciation, an original population (green) range expands and contracts, leaving an isolated fragment population behind. The central population (changed to blue) evolves reproductive isolation in contrast to peripatry.

cept, by which one species gives rise to a daughter species. ${ }^{[15]}$ It is thought that the character traits of the peripherally isolated species become apomorphic, while the central population remains pleisomorphic. ${ }^{[16]}$

Modern cladistic methods have developed definitions that have incidentally removed derivative species by defining clades in a way that assumes that when a speciation event occurs, the original species no longer exists, while two new species arise; this is not the case in peripatric speciation. ${ }^{[8]}$ Mayr warned against this, as it causes a species to lose their classification status. ${ }^{[17]}$ Loren $\mathrm{H}$. Rieseberg and Luc Brouillet recognized the same dilemma in plant classification. ${ }^{[18]}$

\section{Quantum and budding speciation}

The botanist Verne Grant proposed the term quantum speciation that combined the ideas of J. T. Gulick (his observation of the variation of species in semi-isolation), Sewall Wright (his models of genetic drift), Mayr (both his peripatric and genetic revolution models), and George Gaylord Simpson (his development of the idea of quantum evolution). ${ }^{[19]: 114}$ Quantum speciation is a rapid process with large genotypic or phenotypic effects, whereby a new, cross-fertilizing plant species buds off from a larger population as a semi-isolated peripheral population. ${ }^{[20][19]: 114}$ Interbreeding and genetic drift takes place due to the reduced population size, driving changes to the genome that would most likely 
result in extinction (due to low adaptive value). ${ }^{[19]: 115}$ In rare instances, chromosomal traits with adaptive value may arise, resulting in the origin of a new, derivative species. ${ }^{[8][21]}$ Evidence for the occurrence of this type of speciation has been found in several plant species pairs: Layia discoidea and L. glandulosa, Clarkia lingulata and C. biloba, and Stephanomeria malheurensis and S. exigua ssp. coronaria. ${ }^{[8]}$

A closely related model of peripatric speciation is called budding speciation-largely applied in the context of plant speciation. ${ }^{[22]}$ The budding process, where a new species originates at the margins of an ancestral range, is thought to be common in plants ${ }^{[22]}$ —especially in progenitor-derivative species pairs. ${ }^{[23]}$

\section{Centrifugal speciation}

William Louis Brown, Jr. proposed an alternative model of peripatric speciation in 1957 called centrifugal speciation. This model contrasts with peripatric speciation by virtue of the origin of the genetic novelty that leads to reproductive isolation. ${ }^{[24]} \mathrm{A}$ population of a species experiences periods of geographic range expansion followed by periods of contraction. During the contraction phase, fragments of the population become isolated as small refugial populations on the periphery of the central population. Because of the large size and potentially greater genetic variation within the central population, mutations arise more readily. These mutations are left in the isolated peripheral populations, whereby, promoting reproductive isolation. Consequently, Brown suggested that during another expansion phase, the central population would overwhelm the peripheral populations, hindering speciation. However, if the species finds a specialized ecological niche, the two may coexist. ${ }^{[25][26]}$ The phylogenetic signature of this model is that the central population becomes derived, while the peripheral isolates (in this case, the progenitors) become paraphyletic. ${ }^{[16]}$ - the reverse of the general model. In contrast to centrifugal speciation, peripatric speciation has sometimes been referred to as centripetal speciation (see figures 1 and 2 for a contrast). ${ }^{[27]}$ Centrifugal speciation has been largely ignored in the scientific literature, often dominated by the traditional model of peripatric speciation. ${ }^{[28][24][16]}$ Despite this, Brown cited a wealth of evidence to support his model, of which has not yet been refuted. ${ }^{[25]}$
Peromyscus polionotus and $P$. melanotis (the peripherally isolated species from the central population of $P$. maniculatus) arose via the centrifugal speciation model. ${ }^{[29]}$ Centrifugal speciation may have taken place in tree kangaroos, South American frogs (Ceratophrys), shrews (Crocidura), and primates (Presbytis melalophos). ${ }^{[28]}$ John C. Briggs associates centrifugal speciation with centers of origin, contending that the centrifugal model is better supported by the data, citing species patterns from the proposed 'center of origin' within the Indo-West Pacific ${ }^{[28]}$

\section{Kaneshiro model}

When a sexual species experiences a population bottle neck-that is, when the genetic variation is reduced due to small population size-mating discrimination among females may be altered by the decrease in courtship behaviors of males. ${ }^{[11]}$ Sexual selection pressures may become weakened by this in an isolated peripheral population, and as a by-product of the altered mating recognition system, secondary sexual traits may appear. ${ }^{[9]}$ Eventually, a growth in population size paired with novel female mate preferences will give rise to reproductive isolation from the main population-thereby completing the peripatric speciation process. ${ }^{[10]}$ Support for this model comes from experiments and observation of species that exhibit asymmetric mating patterns such as the Hawaiian Drosophila species $^{[30][31]}$ or the Hawaiian cricket Laupala. ${ }^{[32]}$ However, this model has not been entirely supported by experiments, and therefore, it may not represent a plausible process of peripatric speciation that takes place in nature. ${ }^{[1]]}$
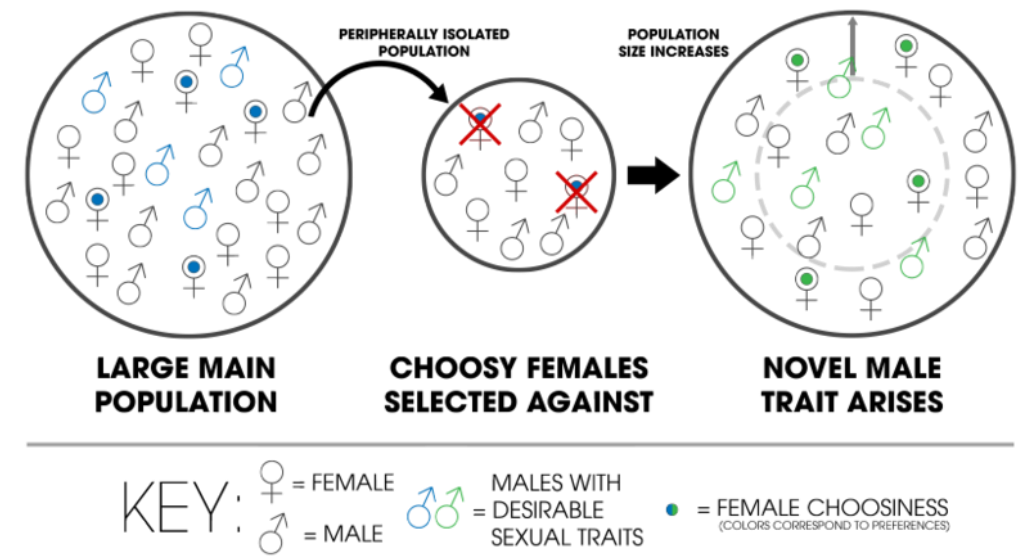

Figure 2 | In the Kaneshiro model, a sample of a larger population results in an isolated population with less males containing attractive traits. Over time, choosy females are selected against as the population increases. Sexual selection drives new traits to arise (green), reproductively isolating the new population from the old one (blue). ${ }^{[11]}$ 


\section{Evidence}

See also: Allopatric speciation \$ Observational evidence

Observational evidence from nature and laboratory experiments support the occurrence of peripatric speciation. Islands and archipelagos are often the subject of speciation studies in that they represent isolated populations of organisms. Island species provide direct evidence of speciation occurring peripatrically in such that, "the presence of endemic species on oceanic islands whose closest relatives inhabit a nearby continent" must have originated by a colonization event. ${ }^{[1]: 106-107}$ Comparative phylogeography of oceanic archipelagos shows consistent patterns of sequential colonization and speciation along island chains, most notably on the Azores islands, Canary Islands, Society Islands, Marquesas Islands, Galápagos Islands, Austral Islands, and the Hawaiian Islands-all of which express geological patterns of spatial isolation and, in some cases, linear arrangement. ${ }^{[33]}$ Peripatric speciation also occurs on continents, as isolation of small populations can occur through various geographic and dispersion events. Laboratory studies have been conducted where populations of Drosophila, for example, are separated from one another and evolve in reproductive isolation.

\section{Hawaiian archipelago}

Drosophila species on the Hawaiian archipelago have helped researchers understand speciation processes in great detail. It is well established that Drosophila has undergone an adaptive radiation into hundreds of endemic species on the Hawaiian island chain; ${ }^{[1]: 107}$ [34] originating from a single common ancestor (supported from molecular analysis). ${ }^{[35]}$ Studies consistently find that colonization of each island occurred from older to younger islands, and in Drosophila, speciating peripatrically at least fifty percent of the time. ${ }^{[1]: 108}$ In conjunction with Drosophila, Hawaiian lobeliads (Cyanea) have also undergone an adaptive radiation, with upwards of twenty-seven percent of extant species arising after new island colonization-exemplifying peripatric speciation-once again, occurring in the old-to-young island direction. ${ }^{[36][37][38]}$

Other endemic species in Hawaii also provide evidence of peripatric speciation such as the endemic flightless crickets (Laupala). It has been estimated that, "17 species out of 36 well-studied cases of [Laupala] speciation were peripatric". ${ }^{1]: 108 ~[39] ~ P l a n t ~ s p e c i e s ~ i n ~ g e n e r a ' s ~ s u c h ~}$ as Dubautia, Wilkesia, and Argyroxiphium have also radiated along the archipelago. ${ }^{[40]}$ Other animals besides insects show this same pattern such as the Hawaiian

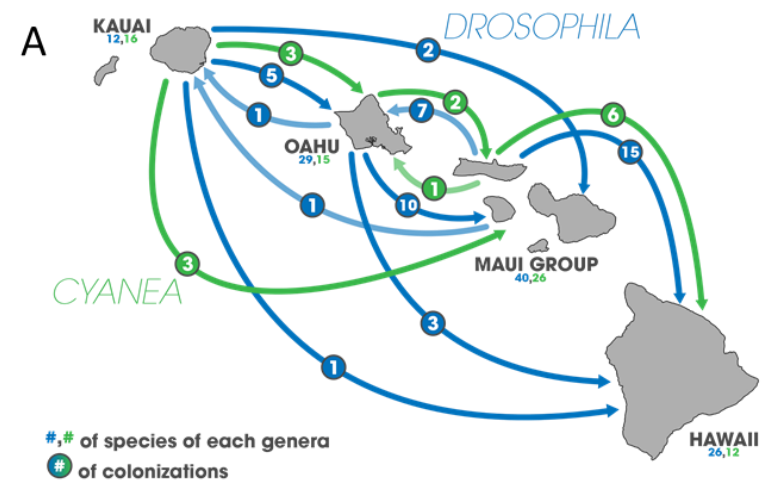

\# of colonizations
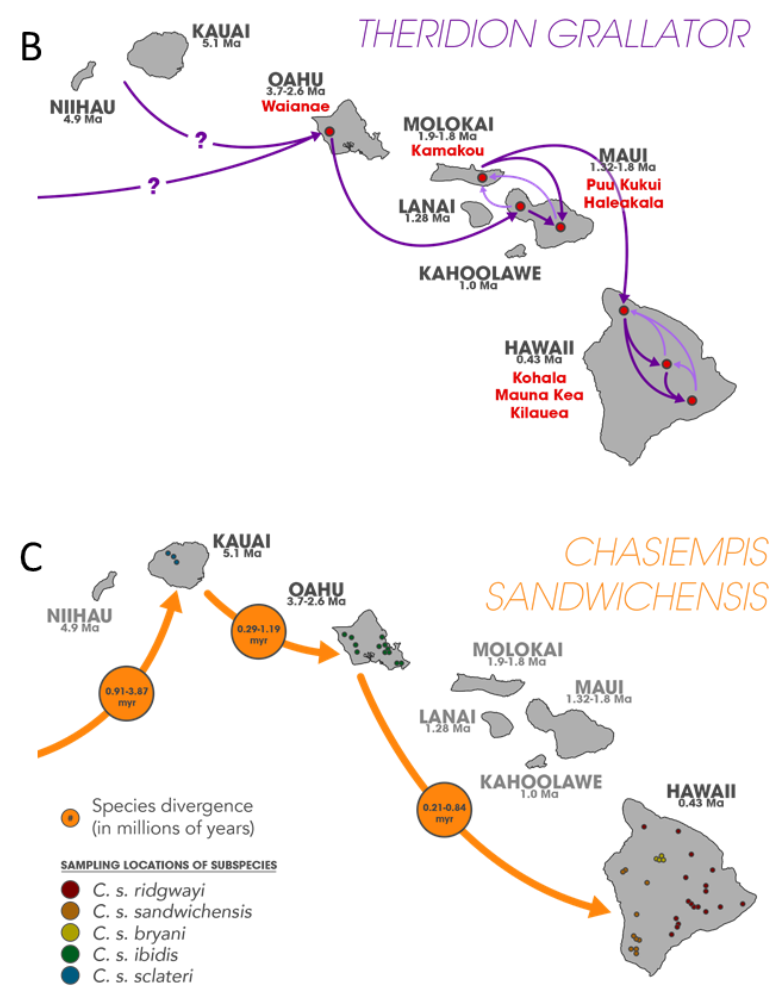

Figure 3 | A) Colonization events of species from the genus Cyanea (green) and species from the genus Drosophila (blue) on the Hawaiian island chain. Islands age from left to right, (Kauai being the oldest and Hawaii being the youngest). Speciation arises peripatrically as they spatiotemporally colonize new islands along the chain. Lighter blue and green indicate colonization in the reverse direction from young-to-old. B) A map of the Hawaiian archipelago showing the colonization routes of Theridion grallatorsuperimposed. Purple lines indicate colonization occurring in conjunction with island age where light purple indicates backwards colonization. T. grallatoris not present on Kauai or Niihau so colonization may have occurred from there, or the nearest continent. C) The sequential colonization and speciation of the 'Elepaio subspecies along the Hawaiian island chain. 
amber snail (Succinea caduca), ${ }^{[41]}$ and 'Elepaio flycatchers (Chasiempis). ${ }^{[42]}$

Tetragnatha spiders have also speciated peripatrically on the Hawaiian islands, ${ }^{[43][44]}$ Numerous arthropods have been documented existing in patterns consistent with the geologic evolution of the island chain, in such that, phylogenetic reconstructions find younger species inhabiting the geologically younger islands and older species inhabiting the older islands ${ }^{[45]}$ (or in some cases, ancestors date back to when islands currently below sea level were exposed). Spiders such as those from the genus Orsonwelles exhibit patterns compatible with the old-to-young geology. ${ }^{[46]}$ Other endemic genera such as Argyrodes have been shown to have speciated along the island chain. ${ }^{[47]}$ Pagiopalus, Pedinopistha, and part of the Thomisidae family have adaptively radiated along the island chain, ${ }^{[48]}$ as well as the Lycosidae family of wolf spiders. ${ }^{[49]}$

A host of other Hawaiian endemic arthropod species and genera have had their speciation and phylogeographical patterns studied: the Drosophila grimshawi species complex, ${ }^{[50]}$ damselflies (Megalagrion xanthomelas and Megalagrion pacificum), ${ }^{[51]}$ Doryonychus raptor, Littorophiloscia hawaiiensis, Anax strenuus, Nesogonia blackburni, Theridion grallator, ${ }^{[52]}$ Vanessa tameamea, Hyalopeplus pellucidus, Coleotichus blackburniae, Labula, Hawaiioscia, Banza (in the Tettigoniidae family), Caconemobius, Eupethicea, Ptycta, Megalagrion, Prognathogryllus, Nesosydne, Cephalops, Trupanea, and the tribe Platynini-all suggesting repeated radiations among the islands. ${ }^{[53]}$

\section{Other islands}

Phylogenetic studies of a species of crab spider (Misumenops rapaensis) in the genus Thomisidae located on the Austral Islands have established the, "sequential colonization of [the] lineage down the Austral archipelago toward younger islands". M. rapaensis has been traditionally thought of as a single species; whereas this particular study found distinct genetic differences corresponding to the sequential age of the islands. ${ }^{[54]}$ The figwart plant species Scrophularia lowei is thought to have arisen through a peripatric speciation event, with the more widespread mainland species, Scrophularia arguta dispersing to the Macaronesian islands. ${ }^{[55][56]}$ Other members of the same genus have also arisen by single colonization events between the islands. ${ }^{[57][58]}$

\section{Species patterns on continents}

The occurrence of peripatry on continents is more difficult to detect due to the possibility of vicariant explanations being equally likely. ${ }^{[1]: 110}$ However, studies concerning the Californian plant species Clarkia bilobaand C. lingulata strongly suggest a peripatric origin. ${ }^{[59]}$ In addition, a great deal of research has been conducted on several species of land snails involving chirality that suggests peripatry (with some authors noting other possible interpretations). ${ }^{[1]: 111}$

The chestnut-tailed antbird Sciaphylax hemimelaena (formerly called Myrmeciza hemimelaena) is located within the Noel Kempff Mercado National Park (Serrania de Huanchaca) in Bolivia. Within this region exists a forest fragment estimated to have been isolated for 1000-3000 years. The population of S. hemimelaena
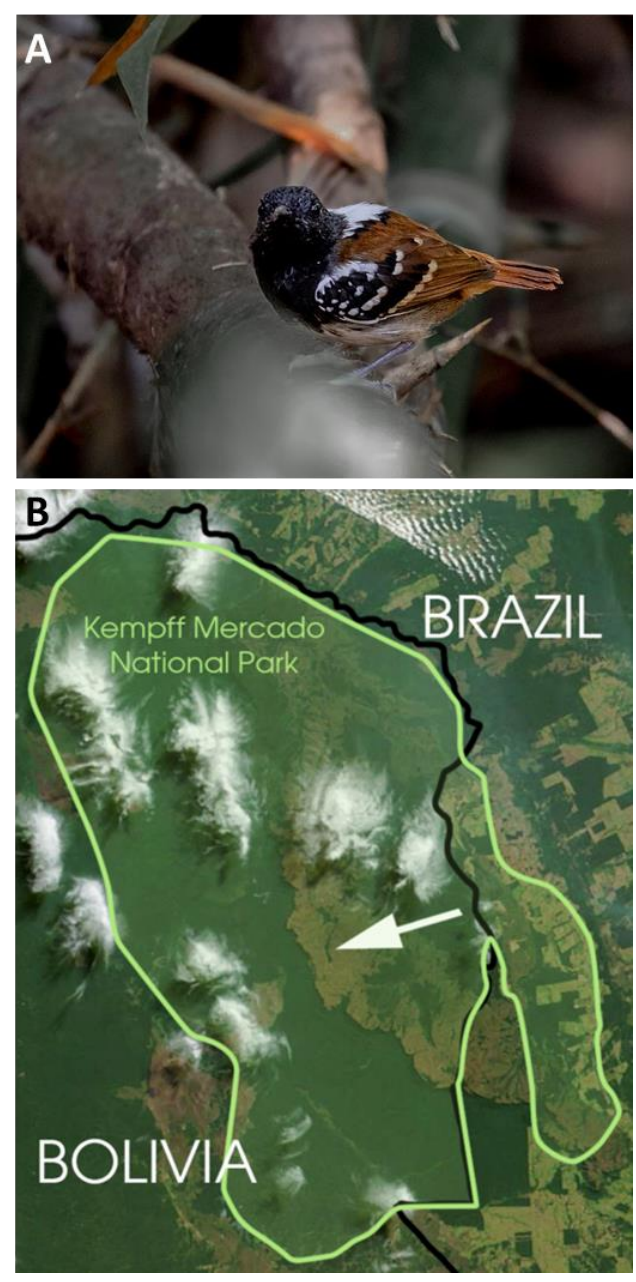

Figure 4 | A) The southern chestnut-tailed antbird, Sciaphylax hemimelaena B) Satellite image of the Noel Kempff Mercado National Park (outlined in green) in Bolivia, South America. The white arrow indicates the location of the isolated forest fragment.

A) Hector Bottai, CC-BY-SA 3.0 

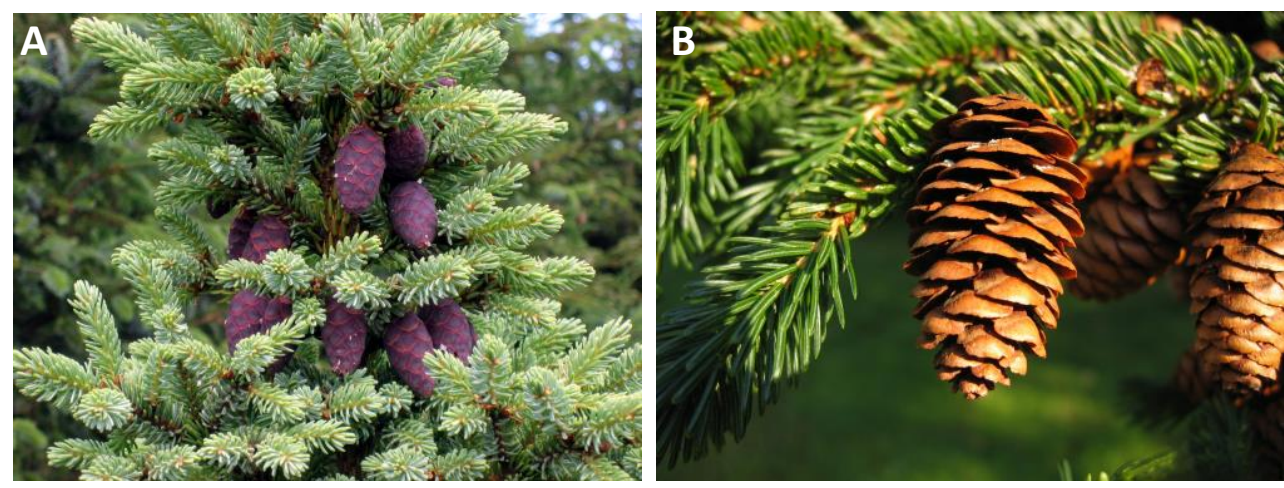

Figure 5 | Foliage and cones of A) Picea mariana, and B) Picea rubens A) MPF, CC-BY-SA 3.0, B) Keith Kanoti, CC-BY 3.0

antbirds that reside in the isolated patch express significant song divergence; thought to be an "early step" in the process of peripatric speciation. Further, peripheral isolation "may partly explain the dramatic diversification of suboscines in Amazonia". [13]

The montane spiny throated reed frog species complex (genus: Hyperolius) originated through occurrences of peripatric speciation events. Lucinda P. Lawson maintains that the species' geographic ranges within the Eastern Afromontane Biodiversity Hotspot support a peripatric model that is driving speciation; suggesting that this mode of speciation may play a significant role in "highly fragmented ecosystems". ${ }^{[2]}$

In a study of the phylogeny and biogeography of the land snail genus Monacha, the species M. ciscaucasica is thought to have speciated peripatrically from a population of $M$. roseni. In addition, $M$. claussi consists of a small population located on the peripheral of the much larger range of $M$. subcarthusiana suggesting that it also arose by peripatric speciation. ${ }^{[60]}$

Red spruce (Picea rubens) has arisen from an isolated population of black spruce (Picea mariana). During the Pleistocene, a population of black spruce became geographically isolated, likely due to glaciation. The geographic range of the black spruce is much larger than the red spruce. The red spruce has significantly lower genetic diversity in both its nuclear DNA and its mitochondrial DNA than the black spruce. ${ }^{[61][62]}$ Furthermore, the genetic variation of the red spruce has no unique mitochondrial haplotypes, only subsets of those in the black spruce; suggesting that the red spruce speciated peripatrically from the black spruce population. ${ }^{[63][64][65]}$ It is thought that the entire Picea genus in North America has been diversified by the process of peripatric speciation, as numerous pairs of closely related species in the genus have smaller southern population ranges; and those with overlapping ranges often exhibit weak reproductive isolation. ${ }^{[66][62]}$ species Cynomys mexicanus speciated peripatrically from Cynomys ludovicianus approximately 230,000 years ago. North American glacial cycles promoted range expansion and contraction of the prairie dogs, leading to the isolation of a relic population in a refugium located in the present day Coahuila, Mexico. ${ }^{[67]}$ This distribution and paleobiogeographic pattern correlates with other species expressing similar biographic range patterns ${ }^{[67]}$ such as with the Sorex cinereus complex. ${ }^{[68]}$

\section{Laboratory experiments}

See also: Laboratory experiments of speciation

Laboratory studies have been conducted in an attempt to replicate peripatric speciation in a controlled setting. Jerry Coyne and H. Allen Orr in Speciation suggest that most laboratory studies of allopatric speciation are also examples of peripatric speciation due to their small population sizes and the inevitable divergent selection that they undergo. ${ }^{[1]: 106}$ Much of the laboratory research concerning peripatry is inextricably linked to founder effect research. Coyne and Orr conclude that selection's role in speciation is well established,

\begin{tabular}{lll}
\hline Species & Replicates & Year \\
\hline Drosophila adiastola & 1 & $1979^{[69]}$ \\
Drosophila silvestris & 1 & $1980^{[70]}$ \\
Drosophila pseudoobscura & 8 & $1985^{[71]}$ \\
Drosophila simulans & 8 & $1985^{[72]}$ \\
Musca domestica & 6 & $1991^{[73]}$ \\
Drosophila pseudoobscura & 42 & $1993^{[74]}$ \\
Drosophila melanogaster & 50 & $1998^{[75]}$ \\
Drosophila melanogaster & $19 ; 19$ & $1999^{[76]}$ \\
Drosophila grimshawi & 1 & $\mathrm{~N} / \mathrm{A}^{[11]}$ \\
\hline
\end{tabular}

Table 1 | A non-exhaustive table of laboratory experiments focused explicitly on peripatric speciation. Most of the studies also conducted experiments on vicariant speciation as well. The "replicates" column signifies the number of lines used in the experiment-that is, how many independent populations were used (not the population size or the number of generations performed). ${ }^{[11]}$ 
whereas genetic drift's role is unsupported by experimental and field data-suggesting that founder-effect speciation does not occur. ${ }^{[1]: 410}$ Nevertheless, a great deal of research has been conducted on the matter, and one study conducted involving populations of Drosophila pseudoobscura found evidence of isolation after a single bottleneck. ${ }^{[77][78]}$

\section{References}

1. Jerry A. Coyne; H. Allen Orr (2004), Speciation, Sinaver Associates, ISBN 087893-091-4

2. Lucinda P. Lawson, John M Bates, Michele Menegon, \& Simon P. Loader (2015), "Divergence at the edges: peripatric isolation in the montane spiny throated reed frog complex", BMC Evolutionary Biology 15 (128), doi:10.1186/s12862-015-0384-3

3. Ernst Mayr. (1954). Change of genetic environment and evolution. In J. Huxley, A. C. Hardy \& E. B. Ford. (eds) Evolution as a Process, Unwin Brothers, London. Pp. 157-180.

4. Ernst Mayr. (1982). Processes of speciation in animals. In A. R. I. Liss. (eds) Mechanisms of Speciation, Alan R. Liss Inc., New York. Pp. 1-19.

5. W. B. Provine (1 July 2004). "Ernst Mayr: Genetics and speciation". Genetics 167 (3): 1041-6. PMID 15280221. PMC 1470966.

6. Alan R. Templeton (1 April 1980). "The theory of speciation via the founder principle". Genetics 94 (4): 1011-38. PMID 6777243. PMC 1214177.

7. Ernst Mayr (1963), Animal Species and Evolution, Harvard University Press

8. L. D. Gottlieb (2003), "Rethinking classic examples of recent speciation in plants", New Phytologist 161, doi:10.1046/j.1469-8137.2003.00922.x

9. Kenneth Y. Kaneshiro (1976), "Ethological isolation and phylogeny in the Plantibia subgroup of Hawaiian Drosophila", Evolution 30 (4), doi:10.1111/j.1558-5646.1976.tb00954.x, PMID 28563322

10. Kenneth Y. Kaneshiro (1980), "Sexual selection, speciation and the direction of evolution", Evolution 34 (3), doi:10.1111/j.15585646.1980.tb04833.x, PMID 28568697

11. Anders Ödeen \& Ann-Britt Florin (2002), "Sexual selection and peripatric speciation: the Kaneshiro model revisited", Journal of Evolutionary Biology 15, doi:10.1046/j.1420-9101.2002.00378.x

12. Michael Turelli, Nicholas H. Barton, \& Jerry A. Coyne (2001), "Theory and speciation", Trends in Ecology \& Evolution 16 (7), doi:10.1016/s01695347(01)02177-2

13. Nathalie Seddon \& Joseph A. Tobias (2007), "Song divergence at the edge of Amazonia: an empirical test of the peripatric speciation model", Biological Journal of the Linnean Society 90, doi:10.1111/j.10958312.2007.00753.x

14. Daniel J. Crawford (2010), "Progenitor-derivative species pairs and plant speciation", Taxon $\mathbf{5 9}$ (5)

15. James S. Albert \& Roberto E. Reis (2011). Historical Biogeography of Neotropical Freshwater Fishes. ISBN 978-0-520-26868-5.

16. Jennifer K. Frey (1993), "Modes of Peripheral Isolate Formation and Speciation", Systematic Biology 42 (3), doi:10.1093/sysbio/42.3.373

17. Ernst Mayr (1992), "A local flora and the biological species concept", American Journal of Botany 79 (2), doi:10.2307/2445111

18. Loren H. Rieseberg and Luc Brouillet (1994), "Are many plant species paraphyletic?", Taxon 43 (1), doi:10.2307/1223457

19. Verne Grant (1971), Plant Speciation, Columbia University Press, ISBN 0231083262

20. Douglas J. Futuyma (1989), "Speciational trends and the role of species in macroevolution", The American Naturalist 134 (2), doi:10.1086/284983

21. Loren H. Rieseberg (2001), "Chromosomal rearrangements and speciation", Trends in Ecology \& Evolution 16 (7)

22. Brian L. Anacker and Sharon Y. Strauss (2013), "The geography and ecology of plant speciation: range overlap and niche divergence in sister species", Proceedings of the Royal Society B 281 (1778), doi:10.1098/rspb.2013.2980

23. Daniel J. Crawford (2010), "Progenitor-derivative species pairs and plant speciation", Taxon $\mathbf{5 9}(5)$

24. Sergey Gavrilets, Hai Li, \& Michael D. Vose (2000), "Patterns of Parapatric Speciation", Evolution $54 \quad$ (4), doi:10.1554/00143820(2000)054[1126:pops]2.0.co;2

25. Daniel J. Howard (2003). "Speciation: Allopatric". eLS(Chichester: John Wiley \& Sons Ltd). doi:10.1038/npg.els.0001748.
26. W. L. Brown Jr. (1957), "Centrifugal speciation", Quarterly Review of Biology 32 (3), doi:10.1086/401875

27. Brian W. Bowen (2010), "Interview with John C. Briggs, recipient of the 2005 Alfred Russel Wallace award", Frontiers of Biogeography 2 (3)

28. John C. Briggs (2000), "Centrifugal speciation and centres of origin", Journal of Biogeography 27, doi:10.1046/j.1365-2699.2000.00459.x

29. Ira F. Greenbaum, Robert J. Baker \& Paul R. Ramsey (1978), "Chromosomal Evolution and the Mode of Speciation in Three Species of Peromyscus", Evolution 32 (3), doi:10.1111/j.1558-5646.1978.tb04609.x, PMID 28567964

30. Kenneth Y. Kaneshiro (1983), "Sexual selection and direction of evolution in the biosystematics of Hawaiian Drosophilidae", Annual Review of Entomology 28, doi:10.1146/annurev.en.28.010183.001113

31. Luther Val Giddings \& Alan R. Templeton (1983), "Behavioral Phylogenies and the Direction of Evolution", Science 220 (4595), doi:10.1126/science.220.4595.372

32. Kerry L. Shaw \& Ezequiel Lugo (2001), "Mating asymmetry and the direction of evolution in the Hawaiian cricket genus Laupala", Molecular Ecology 10 (3), doi:10.1046/j.1365-294x.2001.01219.x

33. Kerry L. Shawa \& Rosemary G. Gillespie (2016), "Comparative phylogeography of oceanic archipelagos: Hotspots for inferences of evolutionary process", PNAS 113 (29), doi:10.1073/pnas.1601078113

34. Hannes Schuler, Glen R. Hood, Scott P. Egan, \& Jeffrey L. Feder (2016), "Modes and Mechanisms of Speciation", Reviews in Cell Biology and Molecular Medicine 2 (3), doi:10.1002/3527600906.mcb.201600015

35. DeSalle R. (1995). Molecular approaches to biogeographic analysis of Hawaiian Drosophilidae. Pp. 72-89 in W.L. Wagner and V.A. Funk (eds.) Hawaiian Biogeography: Evolution on a Hot-Spot Archipeligo. Smithsonian Institution Press, Washington DC.

36. T. J. Givnish (1998). "Adaptive plant evolution on islands: classical patterns, molecular data, new insights". Evolution on islands 281: 304.

37. T. J. Givnish, K. J. Sytsma, W. J. Hahn, and J. F. Smith. (1995). Molecular evolution, adaptive radiation, and geographic speciation in Cyanea (Campanulaceae, Lobeliodeae). Pp. 259-301 in W.L. Wagner and V.A. Funk (eds.) Hawaiian Biogeography: Evolution on a Hot-Spot Archipeligo. Smithsonian Institution Press, Washington DC.

38. Thomas J. Givnish, Kendra C. Millam, Austin R. Mast, Thomas B. Paterson, Terra J. Theim, Andrew L. Hipp, Jillian M. Henss, James F. Smith, Kenneth R. Wood, \& Kenneth J. Sytsma (2009), "Origin, adaptive radiation and diversification of the Hawaiian lobeliads (Asterales: Campanulaceae)", Proc. R. Soc. B 276, doi:10.1098/rspb.2008.1204

39. Kerry L. Shaw (2002), "Conflict between nuclear and mitochondrial DNA phylogenies of a recent species radiation: What mtDNA reveals and conceals about modes of speciation in Hawaiian crickets", PNAS 99 (25), doi:10.1073/pnas.242585899

40. Martha S. Witter (1990), "Evolution in the Madiinae: Evidence from Enzyme Electrophoresis", Annals of the Missouri Botanical Garden 77 (1), doi:10.2307/2399630

41. Brenden S. Holland and Robert H. Cowie (2007), "A geographic mosaic of passive dispersal: population structure in the endemic Hawaiian amber snail Succinea caduca (Mighels, 1845)", Molecular Ecology 16 (12), doi:10.1111/j.1365-294X.2007.03246.x

42. Eric A. VanderWerf, Lindsay C. Young, Norine W. Yeung, \& David B. Carlon (2010), "Stepping stone speciation in Hawaii's flycatchers: molecular divergence supports new island endemics within the elepaio", Conservation Genetics 11 (4), doi:10.1007/s10592-009-9958-1

43. Rosemary G. Gillespie \& H. B. Croom. (1995). Comparison of speciation mechanisms in web-building and non-web-building groups within a lineage of spiders. In W.L. Wagner \& V.A. Funk (eds.) Hawaiian Biogeography: Evolution on a Hot-Spot Archipeligo, Smithsonian Institution Press, Washington DC. Pp. 121-146.

44. Rosemary G. Gillespie (2005), "Geographical context of speciation in a radiation of Hawaiian Tetragnatha spiders (Aranae, Tetragnathidae", The Journal of Arachnology 33, doi:10.1636/05-15.1

45. Rosemary G. Gillespie (2004), "Community Assembly Through Adaptive Radiation in Hawaiian Spiders", Science 303 (5656), doi:10.1126/science.1091875, PMID 14726588

46. Gustavo Hormiga, Miquel Arnedo, and Rosemary G. Gillespie (2003), "Speciation on a Conveyor Belt: Sequential Colonization of the Hawaiian Islands by Orsonwelles Spiders (Araneae, Linyphiidae)", Systematic Biology 52 (1), doi:10.1080/10635150390132786, PMID 12554442

47. Rosemary G. Gillespie, Malia A. J. Rivera, \& Jessica E. Garb. (1998). Sun, surf and spiders: taxonomy and phylogeography of Hawaiian Araneae. Proceedings of the 17th European Colloquium of Arachnology.

48. Jessica E. Garb (1999), "An Adaptive Radiation of Hawaiian Thomisidae: Biogreographic and Genetic Evidence", The Journal of Arachnology 27

49. W. J. Gertsch (1973), "The cavernicolous fauna of Hawaiian lava tubes. 3. Araneae (Spiders)", Pacific Insects 15 
50. Fabio Piano, Elysse M. Craddock, \& Michael P. Kambysellis (1997), "Phylogeny of the Island Populations of the Hawaiian Drosophila grimshawi Complex: Evidence from Combined Data", Molecular Phylogenetics and Evolution 7 (2), doi:10.1006/mpev.1996.0387

51. Steve Jordan, Chris Simon, David Foote, and Ronald A. Englund (2005), "Phylogeographic patterns of Hawaiian Megalagrion damselflies (Odonata: Coenagrionidae) correlate with Pleistocene island boundaries", Molecular Ecology 14 (11), doi:10.1111/j.1365-294X.2005.02669.x

52. Peter J. P. Croucher, Geoff S. Oxford, Athena Lam, Neesha Mody, \& Rosemary G. Gillespie (2012), "Colonization history and population genetics of the color-polymorphic Hawaiian happy-face spider Theridion grallator (Araneae, Theridiidae)", Evolution 66 (9), doi:10.1111/j.15585646.2012.01653.x

53. G. K. Roderick \& R. G. Gillespie (1998), "Speciation and phylogeography of Hawaiian terrestrial arthropods", Molecular Ecology 7, doi:10.1046/j.1365294x.1998.00309.x

54. Jessica E. Garb \& Rosemary G. Gillespie (2006), "Island hopping across the central Pacific: mitochondrial DNA detects sequential colonization of the Austral Islands by crab spiders (Araneae: Thomisidae)", Journal of Biogeography 33 (2), doi:10.1111/j.1365-2699.2005.01398.x

55. Francisco J. Valtueña, Tomás Rodríguez-Riaño, Josefa López, Carlos Mayo, and Ana Ortega-Olivencia (2017), "Peripatric speciation in an endemic Macaronesian plant after recent divergence from a widespread relative", PLOS ONE 12 (6), doi:10.1371/journal.pone.0178459

56. Francisco J. Valtueña, Josefa López, Juan Álvarez, Tomás RodríguezRiaño, and Ana Ortega-Olivencia (2016), "Scrophularia arguta, a widespread annual plant in the Canary Islands: a single recent colonization event or a more complex phylogeographic pattern?", Ecology and Evolution 6 (13), doi:10.1002/ece3.2109

57. María L. Navarro-Péreza, Pablo Vargas, Mario Fernández-Mazuecos, Josefa López, Francisco J. Valtueña, and Ana Ortega-Olivencia (2015), "Multiple windows of colonization to Macaronesia by the dispersalunspecialized Scrophularia since the Late Miocene", Perspectives in Plant Ecology, Evolution and Systematics 17 (4), doi:10.1016/j.ppees.2015.05.002

58. Agnes Scheunert and Günther Heubl (2014), "Diversification of Scrophularia (Scrophulariaceae) in the Western Mediterranean and Macaronesia - Phylogenetic relationships, reticulate evolution and biogeographic patterns", Molecular Phylogenetics and Evolution 70, doi:10.1016/j.ympev.2013.09.023

59. H. Lewis \& M. R. Roberts (1956), "The origin of Clarkia lingulata", Evolution 10, doi: $10.2307 / 2405888$

60. Marco T. Neiber \& Bernhard Hausdorf (2016), "Molecular phylogeny and biogeography of the land snail genus Monacha (Gastropoda, Hygromiidae)", Zoologica Scripta 46 (3), doi:10.1111/zsc.12218

61. Gary J. Hawley \& Donald H. DeHayes (1994), "Genetic diversity and population structure of red spruce (Picea rubens)", Canadian Journal of Botany 72 (12), doi:10.1139/b94-219

62. Juan P. Jaramillo-Correa \& Jean Bousquet (2003), "New evidence from mitochondrial DNA of a progenitor-derivative species relationship between black and red spruce (Pinaceae)", American Journal of Botany 90 (12), doi:10.3732/ajb.90.12.1801

63. J. P. Jaramillo-Correa, J. Bousquet, J. Beaulieu, N. Isabel, M. Perron, \& M. Bouillé (2003), "Cross-species amplification of mitochondrial DNA sequence-tagged-site markers in conifers: the nature of polymorphism and variation within and among species in Picea", Theoretical and Applied Genetics 106 (8), doi:10.1007/s00122-002-1174-z

64. Isabelle Gamache, Juan P. Jaramillo-Correa, Sergey Payette, \& Jean Bousquet (2003), "Diverging patterns of mitochondrial and nuclear DNA diversity in subarctic black spruce: imprint of a founder effect associated with postglacial colonization", Molecular Ecology 12 (4), doi:10.1046/j.1365-294x.2003.01800.x, PMID 12753210

65. Martin Perron, Daniel J. Perry, Christophe Andalo, \& Jean Bousquet (2000), "Evidence from sequence-tagged-site markers of a recent progenitorderivative species pair in conifers", PNAS 97(21), doi:10.1073/pnas.200417097

66. J. W. Wright (1955), "Species crossability in Spruce in relation to distribution and taxonomy", Forest Science 1 (4)

67. Gabriela Castellanos-Morales, Niza Gámez, Reyna A. Castillo-Gámez, \& Luis E. Eguiarte (2016), "Peripatric speciation of an endemic species driven by Pleistocene climate change: The case of the Mexican prairie dog (Cynomys mexicanus)", Molecular Phylogenetics and Evolution 94, doi:10.1016/j.ympev.2015.08.027

68. Andrew G. Hope, Kelly A. Speer, John R. Demboski, Sandra L. Talbot, \& Joseph A. Cook (2012), "A climate for speciation: Rapid spatial diversification within the Sorex cinereus complex of shrews", Molecular Phylogenetics and Evolution 64 (3), doi:10.1016/j.ympev.2012.05.021

69. Lorna H. Arita \& Kenneth Y. Kaneshiro (1979), "Ethological Isolation Between Two Stocks of Drosophila Adiastola Hardy", Proc. Hawaii. Entomol. Soc. 13

70. J. N. Ahearn (1980), "Evolution of behavioral reproductive isolation in a laboratory stock of Drosophila silvestris", Experientia36 (1), doi:10.1007/BF02003975

71. Diane M. B. Dodd \& Jeffrey R. Powell (1985), "Founder-Flush Speciation: An Update of Experimental Results with Drosophila", Evolution 39 (6), doi:10.1111/j.1558-5646.1985.tb05704.x, PMID 28564258

72. John Ringo, David Wood, Robert Rockwell, \& Harold Dowse (1985), "An Experiment Testing Two Hypotheses of Speciation", The American Naturalist 126 (5), doi:10.1086/284445

73. L. M. Meffert \& E. H. Bryant (1991), "Mating propensity and courtship behavior in serially bottlenecked lines of the housefly", Evolution 45 (2), doi:10.1111/j.1558-5646.1991.tb04404.x, PMID 28567864

74. A. Galiana, A. Moya, \& F. J. Ayala (1993), "Founder-flush speciation in Drosophila pseudoobscura: a large scale experiment", Evolution 47 (2), doi:10.1111/j.1558-5646.1993.tb02104.x, PMID 28568735

75. H. D. Rundle, A. Ø. Mooers, \& M. C. Whitlock (1998), "Single founder-flush events and the evolution of reproductive isolation", Evolution 52 (6), doi:10.1111/j.1558-5646.1998.tb02263.x, PMID 28565304

76. A. Ø. Mooers, H. D. Rundle, \& M. C. Whitlock (1999), "The effects of selection and bottlenecks on male mating success in peripheral isolates", American Naturalist 153, doi:10.1086/303186

77. Jeffrey R. Powell (1978), "The Founder-Flush Speciation Theory: An Experimental Approach", Evolution 32 (3), doi:10.1111/j.15585646.1978.tb04589.x, PMID 28567948

78. Diane M. B. Dodd \& Jeffrey R. Powell (1985), "Founder-Flush Speciation: An Update of Experimental Results with Drosophila", Evolution 39 (6), doi:10.1111/j.1558-5646.1985.tb05704.x, PMID 28564258 